\title{
Combined array-comparative genomic hybridization and single-nucleotide polymorphism-loss of heterozygosity analysis reveals complex genetic alterations in cervical cancer Judith N Kloth*1, Jan Oosting ${ }^{1}$, Tom van Wezel1, Karoly Szuhai ${ }^{2}$, Jeroen Knijnenburg ${ }^{2}$, Arko Gorter ${ }^{1}$, Gemma G Kenter ${ }^{3}$, Gert Jan Fleuren ${ }^{1}$ and Ekaterina S Jordanova*1
}

Address: ${ }^{1}$ Department of Pathology, Leiden University Medical Center, Leiden, The Netherlands, ${ }^{2}$ Department of Molecular Cell Biology, Leiden University Medical Center, Leiden, The Netherlands and ${ }^{3}$ Department of Gynecology, Leiden University Medical Center, Leiden, The Netherlands

Email: Judith N Kloth* - J.N.Kloth@lumc.nl; Jan Oosting - J.Oosting@lumc.nl; Tom van Wezel - Tom.van.Wezel@lumc.nl; Karoly Szuhai - K.Szuhai@lumc.nl; Jeroen Knijnenburg - J.Kijnenburg@lumc.nl; Arko Gorter - A.Gorter@lumc.nl; Gemma G Kenter - G.G.Kenter@lumc.nl; Gert Jan Fleuren - G.J.Fleuren@lumc.nl; Ekaterina S Jordanova* - K.Jordanova@lumc.nl

* Corresponding authors

Published: 20 February 2007

BMC Genomics 2007, 8:53 doi:10.1/86/147/-2/64-8-53

This article is available from: http://www.biomedcentral.com/I47I-2164/8/53

(C) 2007 Kloth et al; licensee BioMed Central Ltd.

This is an Open Access article distributed under the terms of the Creative Commons Attribution License (http://creativecommons.org/licenses/by/2.0), which permits unrestricted use, distribution, and reproduction in any medium, provided the original work is properly cited.
Received: 18 October 2006

Accepted: 20 February 2007

\begin{abstract}
Background: Cervical carcinoma develops as a result of multiple genetic alterations. Different studies investigated genomic alterations in cervical cancer mainly by means of metaphase comparative genomic hybridization $(\mathrm{mCGH})$ and microsatellite marker analysis for the detection of loss of heterozygosity (LOH). Currently, high throughput methods such as array comparative genomic hybridization (array $\mathrm{CGH}$ ), single nucleotide polymorphism array (SNP array) and gene expression arrays are available to study genome-wide alterations. Integration of these 3 platforms allows detection of genomic alterations at high resolution and investigation of an association between copy number changes and expression.

Results: Genome-wide copy number and genotype analysis of 10 cervical cancer cell lines by array CGH and SNP array showed highly complex large-scale alterations. A comparison between array CGH and SNP array revealed that the overall concordance in detection of the same areas with copy number alterations (CNA) was above $90 \%$. The use of SNP arrays demonstrated that about $75 \%$ of $\mathrm{LOH}$ events would not have been found by methods which screen for copy number changes, such as array $\mathrm{CGH}$, since these were $\mathrm{LOH}$ events without CNA. Regions frequently targeted by CNA, as determined by array CGH, such as amplification of $5 p$ and $20 q$, and loss of $8 p$ were confirmed by fluorescent in situ hybridization (FISH). Genome-wide, we did not find a correlation between copy-number and gene expression. At chromosome arm $5 p$ however, $22 \%$ of the genes were significantly upregulated in cell lines with amplifications as compared to cell lines without amplifications, as measured by gene expression arrays. For 3 genes, SKP2, ANKH and TRIO, expression differences were confirmed by quantitative real-time PCR (qRT-PCR).

Conclusion: This study showed that copy number data retrieved from either array CGH or SNP array are comparable and that the integration of genome-wide $\mathrm{LOH}$, copy number and gene expression is useful for the identification of gene specific targets that could be relevant for the development and progression in cervical cancer.
\end{abstract}




\section{Background}

The development of cervical cancer is a multi-step process. This process starts with infection of the epithelial layer with high-risk human papilloma virus (HPV). Cervical intraepithelial neoplasia (CIN) grade I, II and III, representing reversible stages of disease, is believed to develop towards neoplasm. From CIN I onwards genomic alterations and aneuploidy can be detected $[1,2]$ and when disease is progressing towards CIN II and III, genetic alterations become more evident [3]. HPV E6 and E7 can induce cellular transformation due to interaction with cellular proteins involved in cell cycle control, apoptosis and genomic instability [4]. The induction of genomic instability seems to be particularly important for the establishment and development of an invasive tumour [5].

So far, different studies have investigated genomic alterations in cervical cancer by means of metaphase comparative genomic hybridization (mCGH) and microsatellite marker analysis for the detection of loss of heterozygosity $(\mathrm{LOH})$. Chromosomal changes involving loss of $2 \mathrm{q}, 3 \mathrm{p}$, $4 p, 4 q, 5 q, 6 q, 11 q, 13 q$ and $18 q$ regions and gain of $1 q$, $3 q, 5 p$ and $8 q$ regions at various stages of disease have been identified [1,6-8]. Some of these imbalances have been associated with decreased survival such as $\mathrm{LOH}$ of $18 \mathrm{q}$ [9] or with the transition from severe dysplasia to invasive carcinoma such as gain of $3 q$ [10]. However, few genes, targeted by these genomic imbalances and possibly involved in carcinogenesis, have been discovered due to the lack of resolution when applying mCGH [11] whereas classical LOH studies are laborious. Array comparative genomic hybridization (array CGH) is an established high resolution method to study the whole genome for chromosomal amplifications and deletions [12]. Although array CGH has relatively few printed elements on the arrays, the strength of this technique is the high spatial resolution [13]. A limitation of array CGH is the lack of genotype information. Therefore, it does not provide information about regions of $\mathrm{LOH}$ without copy number alteration (CNA) such as mitotic recombination or gene conversion events. The under-reprepresentation of $\mathrm{LOH}$ in copy number methods may be very high with up to 2/ 3 of LOH events being undetected because of copy-neutral and copy-gain LOH events, as was found in pancreatic cancer [14]. Recently, high-density oligonucleotide-based single polymorphism arrays (SNP arrays) have been used to identify copy number and LOH of chromosomal regions $[15,16]$. Appropriate software tools for the detection of CNA from SNP data are becoming available. The advantage of a combined SNP-CGH approach is the identification of allele specific gain and loss by SNP array and the robust copy number detection by array CGH.

Different factors, including changes in genome copy number, can disrupt proper gene functioning. A few stud- ies showed correlations between chromosome CNA and gene expression changes of the affected regions $[17,18]$. In this study, genome-wide LOH and copy number analyses of 10 cervical cancer cell lines were investigated using SNP and CGH arrays and the sensitivity to detect CNA by the 2 platforms was compared. We aimed at identifying common regions of gains and losses and determining the influence of CNA on gene expression to find genes involved in cervical carcinogenesis.

\section{Results}

Genome-wide LOH and copy number analyses of 10 cervical cancer cell lines were investigated using SNP and CGH arrays to identify common regions of amplification. Also the two platforms were compared in their sensitivity to detect CNA. Furthermore, data from gene expression arrays were combined with array CGH data to investigate an association between gene expression and copy number.

\section{CGH and SNP-LOH analysis}

Various genomic alterations affecting the majority of chromosomes were found in cervical cancer cell lines. The CGH findings for all amplifications, gains and losses detected in these cell lines are displayed in Figure 1A. Gains or amplifications of 5p, 5q, 8q, 9q, 17q and 20q occurred in most of the cell lines. Physical loss of chromosomal regions at $4 \mathrm{p}, 8 \mathrm{p}, 11 \mathrm{q}, 13 \mathrm{q}$ and $18 \mathrm{q}$, occurred in at least half of the cell lines. Regions frequently targeted by gain or loss with small overlapping regions were present at $8 p, 8 q, 9 p, 11 q$ and $17 q$. The minimal region of overlap at 8p23 involved TUSC3, a tumor suppressor gene that showed loss in 5 cell lines. At 8q24, the minimal region of overlap included $c-M \gamma c$ which showed gain in 8 out of 10 cell lines. Amplification at 9q33-q34 included endoglin, a gene involved in tumor angiogenesis and predictive for metastasis in cervical cancer [19]. Loss at 11q25 involved 2 members of the IgLON family of cell adhesion molecules, OPCML and HNT. The minimal region of overlap at 17q11-q21 included ERBB2 and TOP2A, genes that are amplified in breast cancer [20]. As for SNP-LOH, most chromosome arms were affected by $\mathrm{LOH}$ in the cell lines (Figure 1B). More than 5 overlapping regions of $\mathrm{LOH}$ were evident for chromosome region 5q, 6, 8p, 10q, 11q, $14 \mathrm{q}, 18$ and 20p.

\section{Comparison between SNP and BAC microarray}

Concordance between array CGH and SNP array in the detection of CNA was investigated. Overall, the BAC and SNP arrays identified exactly the same regions of gain in $91 \%$ of cases, when taking an average of all cell lines (Table 1). Similarly, the detection of the same regions with loss between the 2 techniques was on average 94\% (Table 1). Subsequently, we investigated the overlap between copy number loss and LOH and copy number 


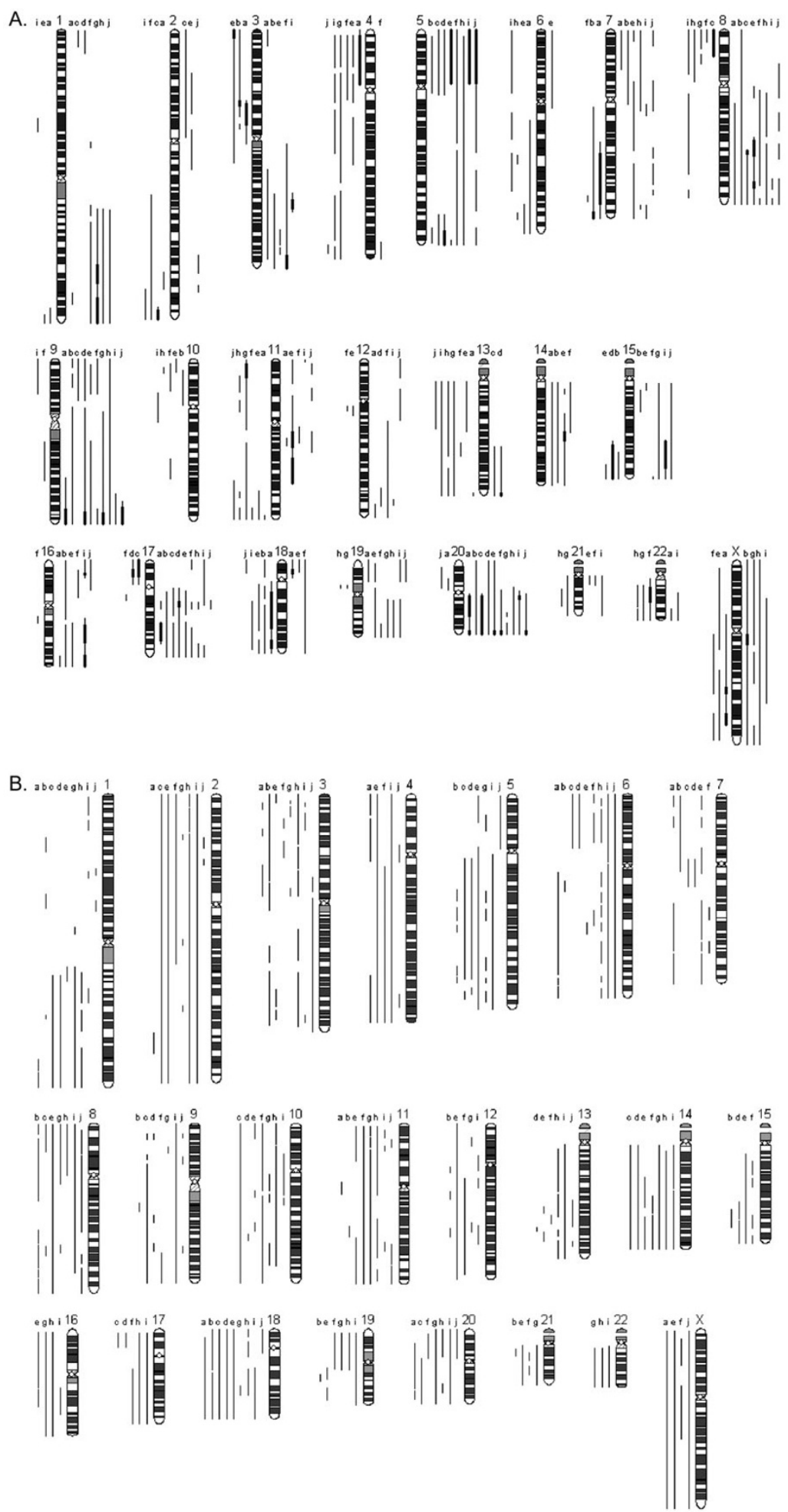

Figure I

Chromosomal gains and losses in cervical cancer cell lines. A) Array CGH results are depicted by lines to the right of the chromosomes as gains and on the left as losses. Thick solid lines represent regions with amplifications of more than I copy loss. B) SNP-LOH results show $\mathrm{LOH}$ as lines on the left side of the chromosomes. The letters above the lines indicate the cell lines: $a)$ CSCC7, b) CSCCI, c) CCII-, d) CCII+, e) CaSki, f) CC8, g) CCIOb, h) CCIOa, i) SiHa and j) HeLa. 
gain and $\mathrm{LOH}$ for both platforms. For $\mathrm{LOH}$ to occur, measured as a reduction in copy number, physical loss is required. Thus all cases with copy number reductions are expected to have undergone LOH. In case of physical loss, around $60 \%$ was observed to encompass regions of $\mathrm{LOH}$ (Table 2). Overall, copy number reductions as measured by array CGH showed a higher overlap with $\mathrm{LOH}$ than SNP array (Table 2), namely $66 \%$ for array CGH and 57\% for SNP array, when taking an average of all cell lines. The occurrence of physical gain involves a change in copy number and thus a change in the proportion of genotypes which would imply a call for LOH. Around 28\% of copy number gain was found to cover regions of LOH (Table 2) and frequencies were comparable between SNP array and array CGH. Also, the overall percentage of LOH in copy neutral, copy gain and copy loss events was investigated for each cell line. The average frequency of LOH from all cell lines was $21-26 \%$ for loss, $17 \%$ for gain and $60 \%$ for copy neutral events (Table 3). Although array CGH and SNP array are comparable in the level of detection of copy number gain and loss, alterations in regions of $\mathrm{LOH}$ were often not found by copy number analysis because these LOH changes did not result in CNA (Figure 1 and Table 3 ). For example, 6 of 10 cell lines showed LOH of $6 p$ while array CGH detected physical loss of $6 p$ in only one cell line. This suggests that the other 5 cell lines underwent mitotic recombination upon loss of one arm, thereby not affecting copy number. Examples of complex genomic alterations are shown for chromosome 8 and 20 of SiHa and chromosome 3 of CaSki (Figure 2). In these examples (Figure 2A and 2B), LOH is caused by loss of one chromosome, accompanied by duplication of the remaining chromosome and subsequent deletions and translocations. The copy number data from SNP array as deduced from the dChip data (in blue lines) and array CGH (red lines) clearly follow the same pattern in these examples, supporting their compliance.

\section{Correlation between DNA copy number and gene expression}

To correlate the chromosomal changes to alterations in gene expression profiles, we have searched for changes in the expression of genes located in the regions targeted by chromosomal gains and deletions. This was done by combining gene expression data from Affymetrix focus arrays with array CGH data. The average gene expression values of all cell lines were used as a reference for each cell line to determine increases or decreases in gene expression. Genome-wide, no correlation was observed between copy-number and expression. Since 5p, 8p23, 8q24, 9q33-q34, 11q25 and 20q are regions with many alterations, we focused on these areas. For 20q we compared cell lines harboring amplifications with cell lines containing gains since no cell line was devoid of $20 \mathrm{q}$ gain or amplification but we did not find significant differences in gene expression. Neither did we find significant changes in gene expression at $8 \mathrm{p} 23,8 \mathrm{q} 24$ and $11 \mathrm{q} 25$. At 9q33-q34, cell lines with amplification (CSCC7, CC11+, CC10A, CC10B, SiHa and HeLa) showed a significantly higher expression compared to cell lines with gains or no CNA correlation for 9 out of 86 genes (10\%); POMT1, FLJ35348, LHX3, NDOR, SH3GLB2, ST6GALNAC4, CDK9, PTAN1 and TRAF2 ( $\mathrm{p}<0.05$, T-test), of which the latter 3 have been implicated in tumorigenesis. Fourteen of 64 genes $(22 \%)$ at $5 p$ showed a significantly higher expression in cell lines with amplification (CaSki, SiHa and HeLa) compared to cell lines with gains or no CNA (Table 4).

\section{Validation of genetic alterations by FISH and LOH}

The DNA copy number retrieved from the array CGHs was validated by FISH. Based on the gained, amplified or lost regions of 5p, 20q and $8 p$, BACs were selected that covered potential oncogenes or tumour suppressor genes. FISH analysis on all cell lines was performed using the BAC clones encompassing SKP2, TRIO, hTERT, GDNF and ANKH genes on 5p, TUSC3 on 8p and ZNF-217, CYP24A1, MYBL2 and AIB1 on 20q (Table 5). Besides additional copies of the area covered by BACs at 5p, other complex genetic alterations such as translocations and inversions were detected (Figure 3A). TUSC3 is a putative tumour suppressor gene at $8 \mathrm{p}$ that is covered by 2 overlapping BAC clones, RP11-44L18 and RP11-184C1 BAC. Loss of the area at $8 \mathrm{p}$ was concordant between array CGH and FISH for CC10A, CC11- and SiHa (Figure 3B). Signals for BACs at chromosome $20 \mathrm{q}$ were equal to the number of centromere signals or showed additional copies (Table 5 and Figure 3C), indicating that the whole arm or the chromosome was gained, which is in agreement with the array CGH data (Figure 1A). Overall, FISH assays confirmed the accuracy in which DNA CNA were detected by array CGH for these loci and highlighted the gains and amplifications of the ZNF-217, CYP24A1, MYBL2 and AIB1 genes at 20q, SKP2, TRIO, hTERT, GDNF and ANKH genes at $5 \mathrm{p}$ and the loss of the TUSC 3 gene at $8 \mathrm{p}$. LOH of $6 \mathrm{p}$ detected by SNP array in cell line CC11-, CC11+ and CC10A was confirmed by $\mathrm{LOH}$ analysis of the tumors from which the cell lines originate, using microsatellite markers (Figure 4).

\section{Validation of gene expression by $q R T-P C R$}

To validate the microarray data, upregulated expression of 3 potential oncogenes (SKP2, ANKH and TRIO) were analyzed by qRT-PCR. These genes were located on $5 p$ that was shown to be gained or amplified by CGH in half of the cell lines. Microarray data showed upregulation of ANKH in 2 of the 3 cell lines with amplification of $5 p$ which did not reach statistical significance. Five normal cervical epithelial cell cultures (NPE) were included in the analysis to investigate the difference in expression level 
Table I: Percentage of gains and losses, determined for array CGH and SNP array data.

\begin{tabular}{|c|c|c|c|c|c|c|}
\hline \multirow[b]{2}{*}{ Cell line } & \multicolumn{3}{|c|}{ Gains } & \multicolumn{3}{|c|}{ Losses } \\
\hline & SNP (\%) & CGH (\%) & Con. (\%) & SNP (\%) & CGH (\%) & Con. (\%) \\
\hline $\mathrm{CSCCl}$ & 20.6 & 26.9 & 88.3 & 14.9 & 10.4 & 94.6 \\
\hline CSCC7 & 16.9 & 16.4 & 93.9 & 16.7 & 12.3 & 95.4 \\
\hline CC8 & 35.7 & 30.2 & 88.6 & 12.5 & 11.3 & 89.6 \\
\hline $\mathrm{CCIOA}$ & 10.3 & 23.5 & 86.9 & 19.7 & 8.2 & 83.4 \\
\hline $\mathrm{CCIOB}$ & 15.9 & 11.2 & 94.4 & 21.7 & 17.4 & 95.4 \\
\hline CCII- & 16.4 & 13.9 & 92.9 & 2.4 & 1.8 & 99.3 \\
\hline $\mathrm{CClI}+$ & 11.0 & 14.5 & 93.9 & 3.5 & 1.8 & 98.3 \\
\hline CasKi & 20.7 & 30.5 & 87.6 & 22.6 & 13.8 & 91.1 \\
\hline $\mathrm{SiHa}$ & 12.6 & 13.7 & 92.7 & 23.1 & 20.9 & 94.1 \\
\hline HeLa & 30.3 & 24.0 & 86.2 & 5.4 & 3.9 & 98.2 \\
\hline Average & 19.0 & 20.5 & 90.5 & 14.3 & 10.2 & 93.9 \\
\hline
\end{tabular}

The percentage of concordance between both techniques is shown in the latter column of gains and losses. Abbreviations: Con. is concordance.

between normal and tumour cells, with and without amplification, from the cervix. Expression was significantly different between cell lines with $5 p$ amplification, cell lines with 5p gains or no $5 p$ alterations, and NPE (Figure 5). At chromosome arm $8 \mathrm{p}$, deletion of the tumour suppressor gene TUSC3, as found by FISH analysis (Table 5 and Figure 3B), was evident in CaSki, SiHa, CC10A, CC11- and $\mathrm{CC} 11+$. No probe set on the expression array was available for TUSC3. Therefore, qRT-PCR was carried out on all cell lines. Only SiHa and CaSki showed a substantial drop in expression, compared to the expression levels of the other cell lines and NPE (data not shown).

\section{Discussion}

The present study describes genome wide LOH and copy number analyses of 10 cervical cancer cell lines using SNP and CGH arrays to identify common regions of amplification and deletion. Also, the sensitivity to detect CNA by the 2 platforms was compared. Furthermore, integrated copy number and gene expression analyses were performed to investigate an association between CNA and gene expression.

CNA retrieved from array CGH and genotype information analyzed from SNP arrays revealed very complex largescale changes. Chromosome arms that were found to be gained and/or amplified in most of the cell lines by array CGH in this study were $5 p, 8 p, 8 q, 9 p, 9 q, 17 q$ and $20 q$. Especially gains of $5 p, 8 q$ and $20 q$ have been frequently reported in cervical cancer $[6,7,10,21-25]$. Also the $1 q$ and $3 q$ arms, often found to be gained $[7,10,21,24-26]$, were overrepresented in 5 of the 10 cell lines. Gains of $17 \mathrm{q}$ and chromosome 9 are less consistently reported $[6,22]$. Gain of $8 \mathrm{q} 24$, present in 8 cell lines, included $c-M \gamma c$ in the minimal region of overlap. Amplification of the $c-M \gamma c$ oncogene is a frequent event in cervical tumors, found in $25 \%$

Table 2: Percentage of overlap between LOH and copy number gains and losses.

\begin{tabular}{|c|c|c|c|c|}
\hline \multirow[b]{3}{*}{ Cell line } & \multicolumn{4}{|c|}{$\%$ overlap between LOH and CNA } \\
\hline & \multicolumn{2}{|c|}{ Gains } & \multicolumn{2}{|c|}{ Losses } \\
\hline & SNP (\%) & CGH (\%) & SNP (\%) & $\mathrm{CGH}(\%)$ \\
\hline $\mathrm{CSCCl}$ & 41.3 & 30.2 & 39.4 & 52.1 \\
\hline $\mathrm{CsCC} 7$ & 13.1 & 14.9 & 72.0 & 92.0 \\
\hline CC8 & 17.8 & 16.9 & 4.8 & 18.2 \\
\hline $\mathrm{CCIOA}$ & 26.6 & 15.7 & 73.9 & 82.2 \\
\hline $\mathrm{CCIOB}$ & 22.1 & 35.4 & 45.6 & 42.4 \\
\hline CCII- & 32.3 & 38.9 & 77.3 & 90.1 \\
\hline $\mathrm{CClI}+$ & 9.1 & 6.9 & 57.2 & 87.5 \\
\hline CasKi & 60.8 & 52.4 & 52.4 & 45.7 \\
\hline $\mathrm{SiHa}$ & 38.1 & 49.6 & 95.7 & 97.0 \\
\hline HeLa & 19.5 & 15.8 & 46.6 & 54.8 \\
\hline Average & 28.1 & 27.7 & 56.5 & 66.2 \\
\hline
\end{tabular}


Table 3: Percentage of LOH determined for copy neutral, copy gain and copy loss events.

\begin{tabular}{|c|c|c|c|c|c|c|}
\hline \multirow[b]{3}{*}{ Cell line } & \multicolumn{6}{|c|}{$\% \mathrm{LOH}$} \\
\hline & \multicolumn{2}{|c|}{ Copy neutral } & \multicolumn{2}{|c|}{ Gain } & \multicolumn{2}{|c|}{ Loss } \\
\hline & SNP (\%) & CGH (\%) & SNP (\%) & CGH (\%) & SNP (\%) & CGH (\%) \\
\hline $\mathrm{CSCCl}$ & 25.7 & 30.4 & 43.9 & 41.8 & 30.3 & 27.7 \\
\hline $\mathrm{CSCC} 7$ & 17.5 & 19.8 & 12.8 & 14.1 & 69.6 & 66.0 \\
\hline CC8 & 79.1 & 78.5 & 19.0 & 15.3 & 1.7 & 6.2 \\
\hline CCIOA & 62.7 & 77.6 & 5.9 & 7.9 & 31.3 & 14.4 \\
\hline $\mathrm{CCIOB}$ & 52.3 & 59.6 & 12.5 & 14.2 & 35.2 & 26.2 \\
\hline CCII- & 80.1 & 80.7 & 14.7 & 14.9 & 5.2 & 4.4 \\
\hline $\mathrm{CClI}+$ & 83.6 & 86.1 & 5.5 & 5.5 & 10.9 & 8.4 \\
\hline CasKi & 53.4 & 60.0 & 20.5 & 26.6 & 26.0 & 13.7 \\
\hline $\mathrm{SiHa}$ & 54.6 & 54.2 & 8.1 & 11.5 & 34.3 & 37.3 \\
\hline HeLa & 63.3 & 74.1 & 25.8 & 16.6 & 10.9 & 9.4 \\
\hline Average & 57.2 & 62.1 & 16.9 & 16.8 & 25.5 & 21.4 \\
\hline
\end{tabular}

to more than half of the tumours $[27,28]$. Chromosome arms affected by loss in half, or more, of the cell lines were $4 p, 8 p, 11 q$ and $13 q$ of which especially $4 p$ and $13 q$ have been reported regularly in cervical cancer $[7,10,22,25,26,29]$. Six cell lines showed loss of $11 \mathrm{q} 25$ that includes OPCML in the minimal region of overlap. OPCML is a tumour suppressor gene in epithelial ovarian cancer [30]. Although the genotype data have to be interpreted with some caution because of the use of cell lines, many of the frequent changes that we observed were in concordance with previous studies.

The SNP-LOH array data showed that most chromosome arms were affected by LOH in the cell lines. More than 5 overlapping regions of $\mathrm{LOH}$ were evident for chromosome region $5 \mathrm{q}, 6 \mathrm{p}, 6 \mathrm{q}, 8 \mathrm{p}, 10 \mathrm{q}, 11 \mathrm{q}, 14 \mathrm{q}, 18 \mathrm{p}, 18 \mathrm{q}$ and 20p. LOH of the majority of these chromosomes, specifically $5 \mathrm{q}, 6 \mathrm{p}, 8 \mathrm{p}, 10 \mathrm{q}, 11 \mathrm{q}$ and 18 , has been reported previously as frequent events in cervical cancer $[9,31,32]$. Whereas LOH of $8 p$ resulted in copy number loss, $\mathrm{LOH}$ of 6p did not result in CNA for most cases, indicative of mitotic recombination events.

A comparison between CGH and SNP array revealed that the overall concordance in detection of the same areas with CNA was on average $91 \%$ for gain and $94 \%$ for loss (Table 1). Thus both platforms are comparable in the detection of particular regions with gain or loss. Additionally, the use of high-density SNP arrays showed that cervical cancer cell lines harbor multiple regions of $\mathrm{LOH}$ which are not detected by methods which screen for CNA such as array CGH. Accordingly, comparison of array CGH and SNP array in genome-wide analysis shows that detection of CNA by SNP array is reliable and has the added advantage of providing genotype information. However, LOH was not consistently detected by SNP array because many copy number changes did not result in true reduction to homozygosity since most of the cervical cancer cell lines are multiploid (Figure 2C and Table 2). As expected, the areas with gain and amplification showed less $\mathrm{LOH}$ than regions with deletion. The overlap between copy-reduction regions and $\mathrm{LOH}$ was $10 \%$ higher for array CGH than for SNP array (Table 2), which suggests that array CGH is slightly better in assigning the correct regions for CNA. Although some regions of LOH are missed, thereby particularly underestimating the amount of $\mathrm{LOH}$ in areas with gain and amplification, an estimation was made for the distribution of LOH in regions with loss, gain and copyneutral regions. We found that copy-neutral and copygain regions accounted for around $75 \%$ of all $\mathrm{LOH}$ identified (17\% represented copy-gain LOH) while LOH associated with copy-reduction occurred at a rate of about $25 \%$ (Table 3). These percentages are similar to a recently published paper from Calhoun et al. that described only $32 \%$ of $\mathrm{LOH}$ events to be associated with copy-reduction [14]. Further improvement in the data from the SNP arrays may be possible using higher density SNP arrays, thereby increasing resolution and the ability to assess subtle copy number changes.

Genome-wide, we did not find a correlation between copy-number changes and expression. Lack of an association may be due to the different histological types from which the cell lines originate (Squamous carcinoma, Adenocarcinomas and Adenosquamous carcinomas) with complex genetic aberrations. Besides increased DNA dosage which may result in overexpression, transcription is influenced by other factors such as the presence and quantity of transcription and repressive factors; CpG methylation; histone methylation and acetylation status, and possibly microRNA's [33]. Thus, amplification or deletion on its own does not have to be a prerequisite for a change 


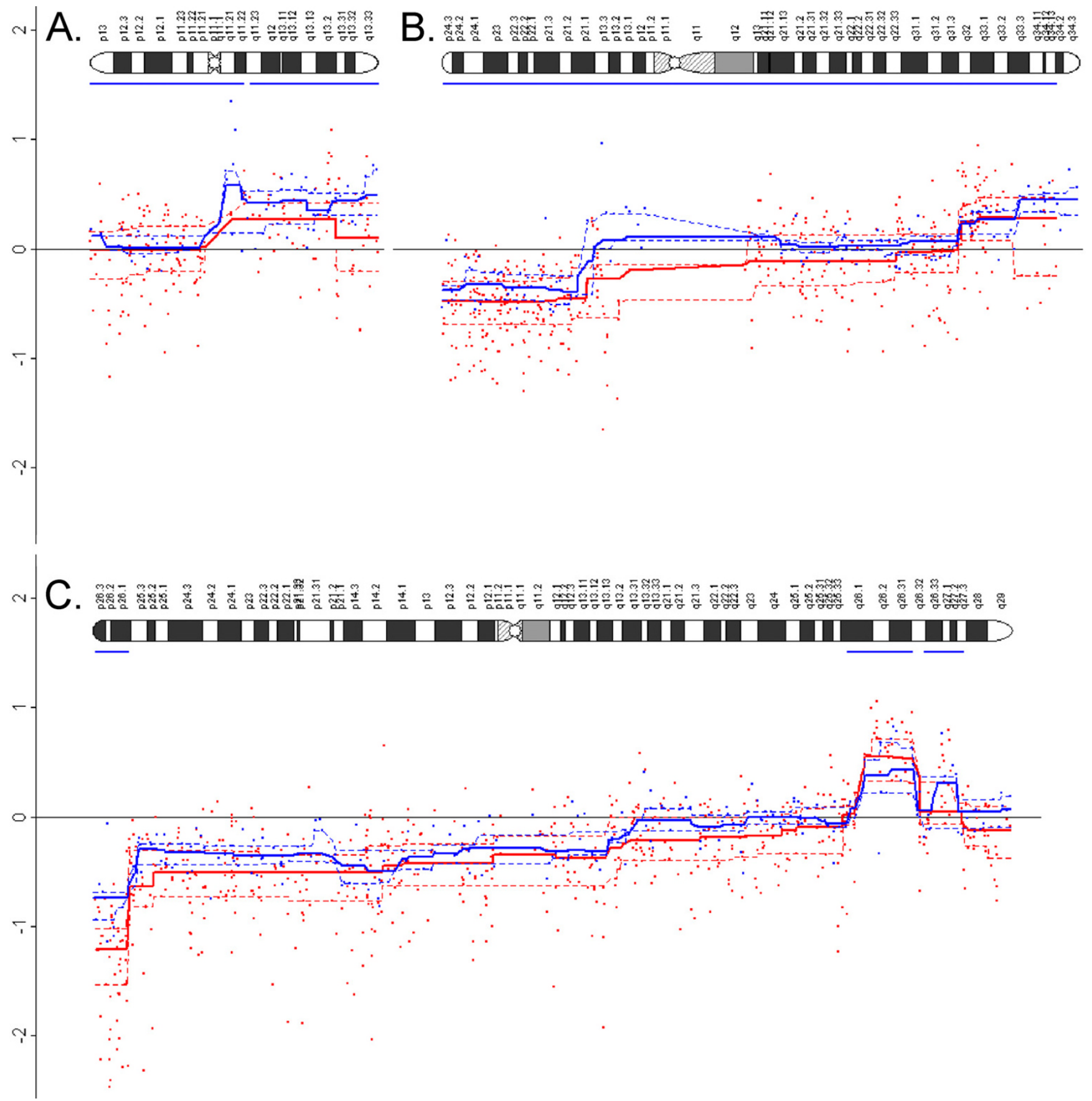

Figure 2

Complex genomic alterations of chromosome 20 (A) and chromosome 8 (B) of SiHa and chromosome 3 of CaSki (C). Below each chromosome ideogram, SNP array data are shown in blue and array CGH data in red. The blue line directly beneath the ideogram depicts LOH, whereas the blue line shifting around the baseline (0) shows copy number retrieved from SNP array data. The dotted blue and red lines represent the confidence intervals for the copy number of the SNP and the CGH array, respectively.

in gene expression. Amplification of 5p, however, correlated with a significant higher gene expression for $22 \%$ of the genes, including SKP2, TRIO, OSMR, RPL37 and PDCD6 (Table 4). The latter genes were previously reported in cancer, either associated with increased expression or with growth stimulatory properties [34-38]. 
Table 4: Genes significantly overexpressed in cell lines with amplification of $5 p$ (T-test, $p<0.05)$.

\begin{tabular}{ll}
\hline Gene symbol & Chromosomal Location \\
\hline ARSB & chr5pll \\
RPL37 & chr5pl3 \\
SKP2 & chr5pl3 \\
OSMR & chr5pl3.I \\
TARS & chr5pl3.2 \\
RADI & chr5pl3.2 \\
SUBI & chr5pl3.3 \\
RNASEN & chr5pl3.3 \\
POLS & chr5pl5 \\
SDHA & chr5pl5 \\
TRIO & chr5pl5.l-pl4 \\
NDUFS6 & chr5pl5.33 \\
TRIPI3 & chr5pl5.33 \\
PDCD6 & chr5pter-pl5.2 \\
\hline
\end{tabular}

Array CGH findings of CNA at 5p, $8 \mathrm{p}$ and $20 \mathrm{q}$ were confirmed by FISH analysis. Gains and amplifications at 5p, as found by array CGH, were validated by BACs covering candidate oncogenes, SKP2, TRIO, ANKH, GDNF and hTERT. SKP2 is important for cell cycle progression and its inhibition decreases proliferation of tumour cells [39]. Besides gain of the region covering the SKP2 gene, we found a significant increase in expression between normal cervical epithelial cells, tumour cells without amplification and tumour cells with amplification. Correlation between amplification of chromosome $5 p$ and increased expression of SKP2 was previously shown in HPV-immortalized keratinocytes [40]. Upregulated expression of SKP2, ANKH and TRIO, as determined by qRT-PCR in cell lines with $5 \mathrm{p}$ amplification, confirmed gene expression data from Affymetrix focus arrays. TRIO, which has a putative role in cell cycle regulation, was found to be amplified and highly expressed in bladder cancer [35] that associated with proliferation and invasive phenotype. ANKH, which is involved in tissue calcification [41], was found to be amplified in bladder cancer [35] and small cell lung cancer cell lines [42]. Thus, upregulation of expression through amplification may be the case for TRIO, ANKH and SKP2 in some neoplasms, including cervical cancer, as indicated by our data. This may hold for hTERT and PRKAA1 as well since it was reported that amplification at $5 \mathrm{p}$ in cervical cancer correlated with increased gene and/ or protein expression $[43,44]$. The telomeric region at $8 \mathrm{p}$ includes a candidate tumour suppressor gene, TUSC3 $[45,46]$. However, physical loss of this region did not correlate with a decrease in gene expression of TUSC3, as determined by qRT-PCR. All cell lines showed gains or amplifications of 20q, a chromosome arm which is often amplified in cancer, including cervical cancer $[10,22,24,47]$. At 20q increased copy numbers, detected by array CGH, were confirmed by FISH. Candidate oncogenes, ZNF-217, CYP24A1, MYBL2 and AIB2, encompassing the region analyzed by FISH, were previously reported to be amplified in other types of cancer as well [48-50]. However, no significant difference in gene expression was found between tumours with gain and tumours with amplification of 20q. Also in oesophageal adenocarcinoma, no correlation was detected between amplification

Table 5: Aberrations determined by FISH analysis at chromosomes 5, 8 and 20.

\begin{tabular}{|c|c|c|c|c|c|c|c|c|c|c|c|c|}
\hline Gene & Location & BAC clone & $\mathbf{I}$ & 7 & 8 & $10 a$ & IOb & II- & $I I+$ & $\mathbf{S}$ & C & $\mathbf{H}$ \\
\hline SKP2 & $5 p \mid 3.2$ & RPII-624K2 & - & - & - & - & - & - & - & G & G & G \\
\hline TRIO & $5 p \mid 5.2$ & RPII-II50G22 & - & - & - & - & - & - & - & G & G & G \\
\hline hTERT & $5 p 15.33$ & RPII-II7B23 & - & - & - & - & - & - & - & G & G & G \\
\hline GDNF & $5 p 13.2$ & RPII-9|4H3 & - & - & - & - & - & - & - & G & G & G \\
\hline ANKH & $5 p 15.2$ & RPII-99II & - & G & - & G & G & G & - & G & G & G \\
\hline TUSC3 & $8 p 22$ & $44 \mathrm{LI} / 8 / 184 \mathrm{Cl}$ & - & - & - & $\mathrm{L}$ & - & $\mathrm{L}$ & L & L & $\mathrm{L}$ & - \\
\hline ZNF-2I7 & $20 q 13.2$ & RP4-724EI6 & G & - & G & G & G & - & - & - & - & G \\
\hline CYP24AI & $20 q \mid 3.2$ & RP5-I075G2I & G & - & G & G & G & - & - & - & - & G \\
\hline MYBL2 & $20 q 13.12$ & RPII-I53L9 & G & - & G & G & G & - & - & - & - & G \\
\hline AIBI & $20 q 12$ & RPII-II5ICI & G & - & G & G & G & - & - & - & - & G \\
\hline
\end{tabular}

(-) no aberration; G - gain; L - loss. Cell lines: I - CSCCI; 7 - CSCC7; 8-CC8; 10a - CCIOA; I0b-CCIOb; II - CCII-; II+-CCII+; S- SiHa, C - CaSki, H - HeLa. 

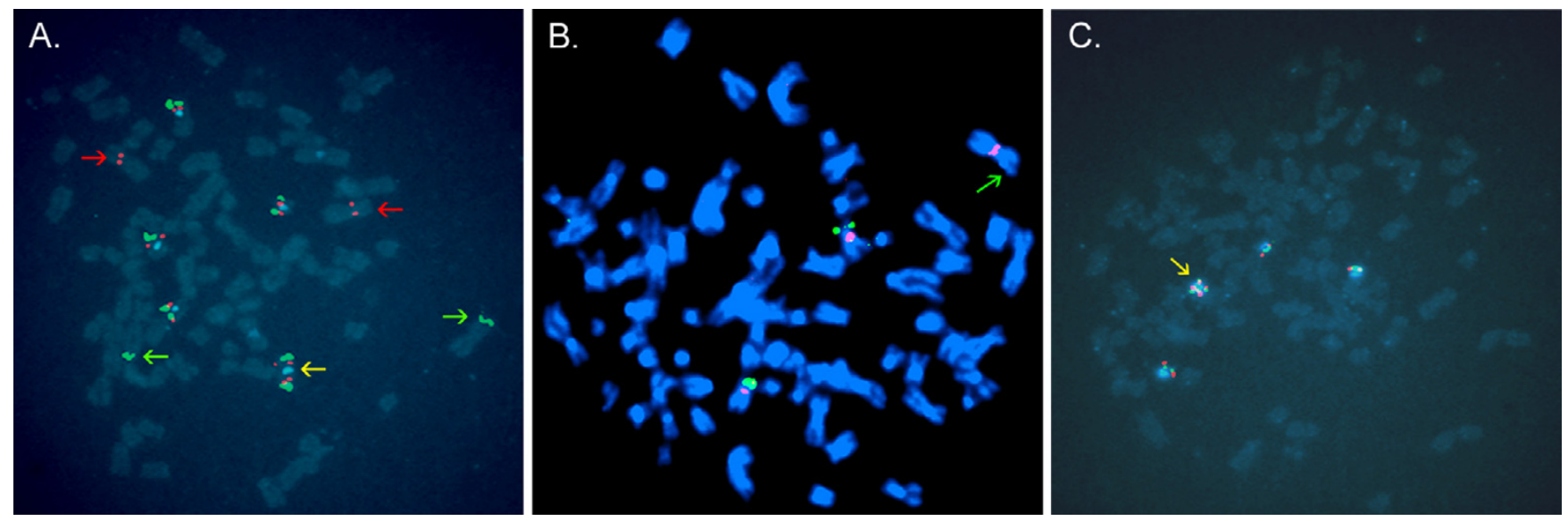

Figure 3

FISH of metaphase preparations depicting copy number alterations. A) CaSki -5 chromosomes 5 (centromere 5-blue; TRIOgreen; SKP2-red); one isochromosome 5p (yellow arrow), 2 translocations of RPI I-II50G22, encompassing TRIO (green arrow) and 2 translocations of RPI I-624K2, encompassing SKP2 (red arrow). B) CaSki -3 chromosomes 8 (centromere 8red, TUSC3-green) with loss of one copy the BACs encompassing TUSC3, RPI I-44LI8/I84CI (green arrow). C) HeLa -4 chromosomes 20 (centromere 20-blue, ZNF-217-red, CYP24A I-green); one isochromosome 20q (yellow arrow).

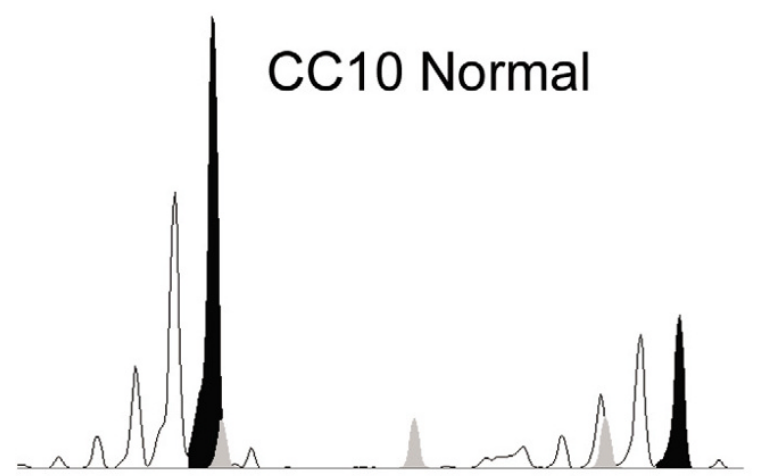

CC10 Tumour

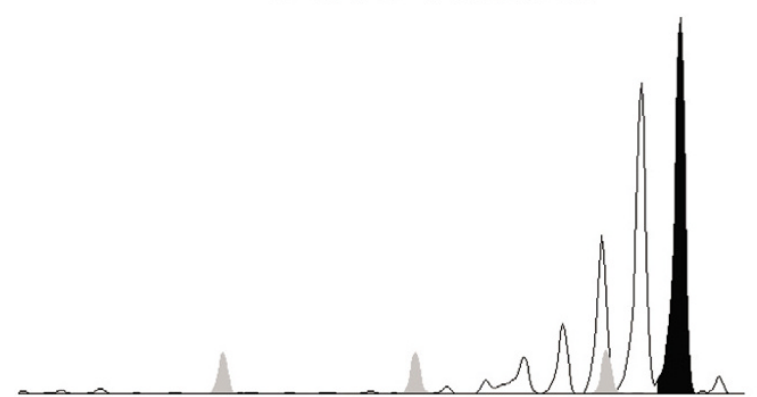

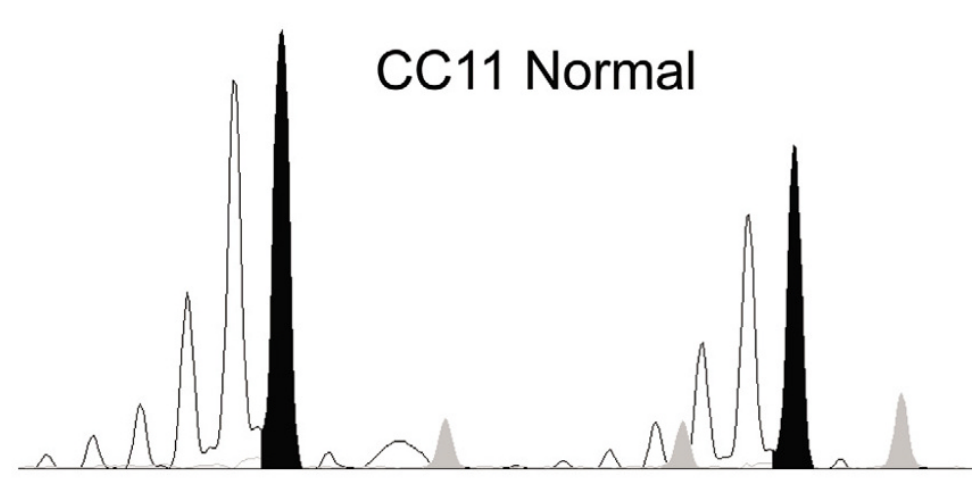

CC11 Tumour

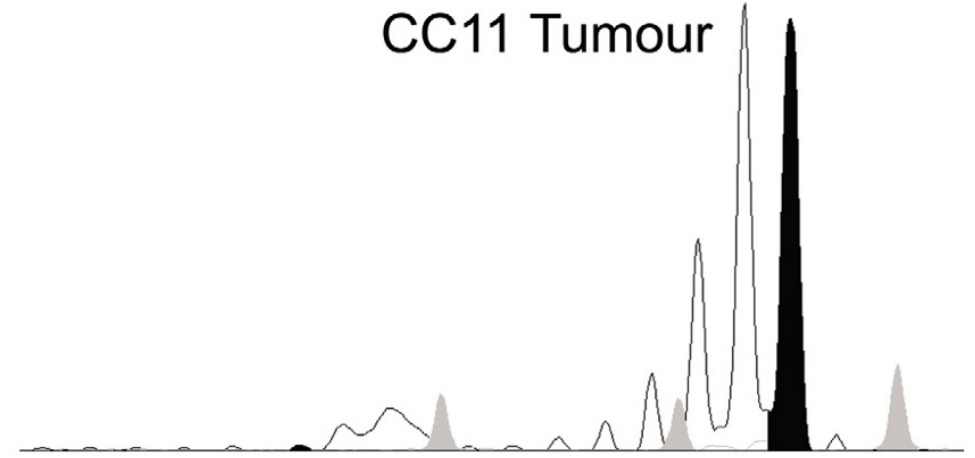

\section{Figure 4}

$\mathrm{LOH}$ at 6p2I.3 is demonstrated for microsatellite marker CI25. Tumour samples from which cell lines $\mathrm{CCI}$ I and CCIO originated were analyzed for $\mathrm{LOH}$. In black the particular alleles are depicted and in grey the marker is shown. 

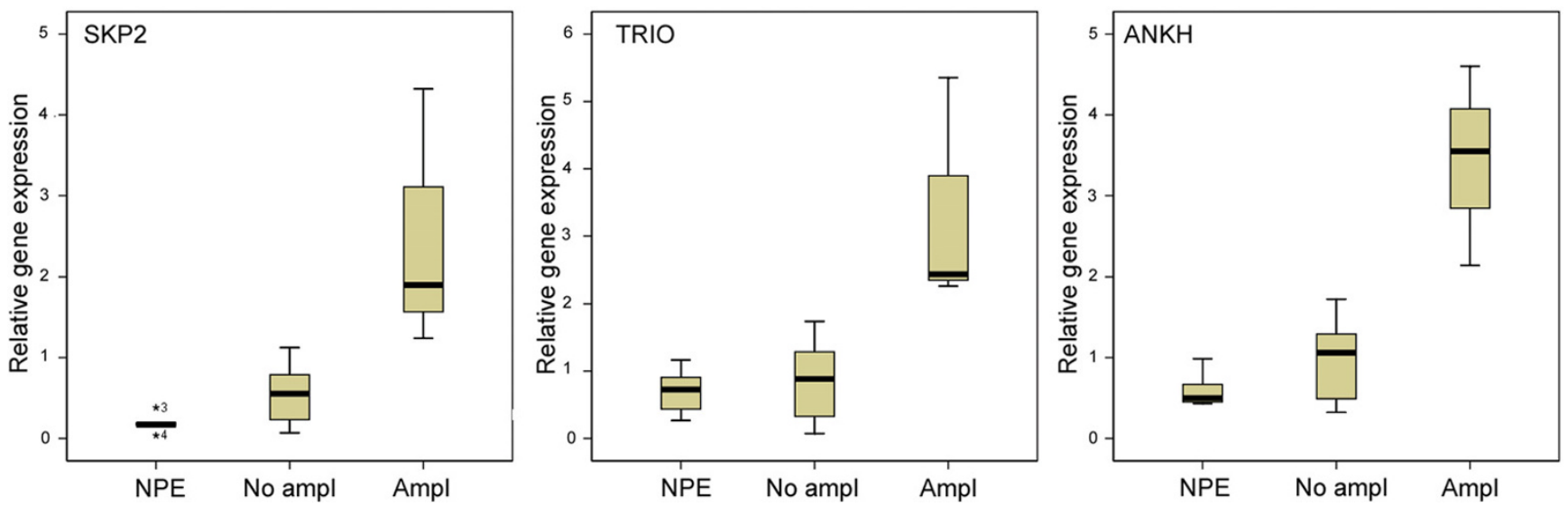

Figure 5

Box plots show differences in gene expression measured by qRT-PCR of SKP2 ( $p=0.003$, ANOVA); TRIO ( $<<0.001$, ANOVA) and ANKH ( $<<0.00$ I, ANOVA) in cell lines with and without amplification of $5 p$ and normal cervical epithelial cell cultures (NPE). Ampl: amplification.

of ZNF-217/CYP24A1 at 20q and increased mRNA expression

[51].

\section{Conclusion}

From this study we conclude that copy number data retrieved from either array CGH or SNP are comparable. The SNP array provided a reliable copy number as well as genotype information, which was suitable for the analysis of complex genetic alterations present in cervical cancer cell lines. Frequently occurring gains, amplifications and deletions on chromosome arms 5p, 20q and 8q were verified by FISH. Amplification at 5p associated with overexpression of candidate oncogenes. Accordingly, the possibility to integrate genome-wide $\mathrm{LOH}$, copy number and gene expression is useful for the identification of gene specific targets that could be relevant for the development and progression in cervical cancer.

\section{Methods}

\section{Cell lines, cultures and patient material}

Human cervical cancer cell lines, HeLa, SiHa, CaSki (ATCC, Rockville, MD), CSCC1, CSCC7, CC8, CC10A, CC10B, CC11-, and CC11+ [52] were maintained in RPMI 1640 (Life Technologies, Grand Island, NY), supplemented with $10 \%$ fetal calf serum, streptomycin and penicillin at $37^{\circ} \mathrm{C}$ in a humid atmosphere containing $5 \%$ $\mathrm{CO}_{2}$. CC10A, CC10B, CC11- and CC11+ are sub clones from the same cell line, CC10 and CC11 respectively. Five normal primary cervical epithelial cell cultures (NPE) were prepared as described [53]. Two archival formalinfixed, paraffin-embedded cervical carcinomas were obtained from the tissue bank of the Department of Pathology (LUMC, Leiden, The Netherlands).

\section{DNA and RNA isolation}

DNA from all the cultured cell lines was isolated using the salting out procedure according to Miller and Polesky [54]. Total RNA was isolated using TRIzol reagent (Gibco BRL/Life Technologies, Breda, The Netherlands) from cells that were grown to approximately $60 \%$ confluence in $250 \mathrm{ml}$ culture flasks (Greiner, Frickenhausen, Germany). Total RNA was cleaned with Rneasy cleanup system columns (Qiagen GmbH, Hilden, Germany).

\section{Array CGH}

Array CGH was performed as previously described [55]. Slides containing $~ 3,500$ BACs in triplicate were made at the Leiden University Medical Centre. The particular BAC set used (Welcome Trust Sanger Institute (UK)) comprises clones spaced at $\sim 1 \mathrm{Mb}$ density over the full genome, a set of subtelomeric sequences for each chromosome arm, and a few hundred probes selected for their involvement in oncogenesis. Information regarding the full set is available in the "Cytoview" window of the Sanger Center mapping database site, Ensembl[56]. The test/reference ratios were normalized for the median of the ratios of all features. The BioConductor package Limma (Smyth and Speed 2003) version 2.6.0 was used to perform background correction with method 'Edwards' and within array normalization with method 'Printtiploess', between array normalization was not performed. After normalization the replicate spots were averaged. Probes with less than 2 valid replicate values, and probes that showed a standard deviation above 0.1 between the replicate values were excluded. Chromosomal regions demonstrating a ratio of between 1.11 and 1.41 were scored as 'gained' and a ratio of 1.41 or greater was scored as 'amplified'. Chro- 
mosomal regions showing a ratio of between 0.84 and 0.73 were scored as lost whereas a second threshold for loss was set for regions showing a ratio of less than 0.73 .

\section{SNP IOK array}

Affymetrix 10K SNP array (Santa Clara, CA) containing 11,555 biallelic polymorphic sequences randomly distributed throughout the genome, excluding the Y chromosome, was used. The median distance between SNPs is $\sim 105 \mathrm{~kb}$. The average heterozygosity for these SNPs is 0.37 , with an average minor allele frequency of 0.25 . DNA samples, including two control DNA samples from Affymetrix, were assayed according to the manufacturer's manual protocol (GeneChip Mapping Assay manual). Genotyping was performed using GDAS (Affymetrix, Santa Clara, CA) and copy number values were calculated using dChip version 1.3. Stretches of homozygous SNPs equal or longer than 24 calls were defined as LOH.

\section{Gene expression microarray}

Affymetrix focus arrays (Santa Clara, CA), representing 8,793 human sequences from the NCBI Refseq database, were used for mRNA expression profiling according to the manufacturer's instructions. Data files of all microarrays were normalized using the Robust Multi-Chip Average (GCRMA) method [57]. Quality control was performed on the arrays using Affy-Probe Level Model (AffyPLM) [58]. Microarrays for each cell line were performed in duplicate. The signal intensities of the replicates were averaged after normalization. To identify differentially expressed genes between cell lines with and without gain, amplification or deletion of a chromosome arm or region, unpaired two-sample t-tests were performed.

\section{Integrative analysis}

To compare the data from the 3 high dimensional techniques; array CGH, SNP array, and expression array, the copy number and expression values were transformed to contain $\log 2$, median centered values. Access to complete microarray data sets will be available at NCBI Gene Expression Omnibus. Normalization of array CGH data and expression arrays resulted in values that are equivalent to $\log 2$ intensity values. The data retrieved from dChip version 1.3 from the SNP arrays showed a copy number of 2 for unaffected probes on a linear scale. These data were divided by 2 and $\log 2$ transformed. A per gene median centering to zero was performed. Array CGH smoothing was performed using a smoother that retains sharp transitions between regions with genomic alterations. The correlation between gene expression and physical genomic alterations was determined by computing the Pearson correlation between the expression of each gene to the smoothed array CGH value of the nearest $\mathrm{BAC}$ on the chromosome. The resulting p-values were subjected to the Benjamini and Yekutieli false discovery rate procedure [59]. The data retrieved from dChip version 1.3 from the SNP arrays showed a copy number of 2 for unaffected probes on a linear scale.

\section{Fluorescent in situ hybridization (FISH)}

Metaphase preparations of all cell lines were obtained using colcemid according to standard procedures [60]. BAC probes for the genes selected on chromosome 5, chromosome 8 and chromosome 20 (Table 5) were ordered from the BACPAC Resource Centre at Children's Hospital Oakland Research Institute (Oakland, CA). All BAC probes were fluorescein-12-dUTP- or digoxigenin12-dUTP-labelled (Roche, Basel, Switzerland). The following centromere probes were used: the $\mathrm{pG}-\mathrm{A} 16$ probe for centromere 5; the D8Z2 probe for centromere 8; and the p3.4 probe for chromosome 20. All centromere probes were kindly provided by J. Wiegant (Department of Molecular and Cellular Biology, LUMC) and labelled with biotin-16-dUTP (Roche, Basel, Switzerland). Triplecolour FISH experiments were performed as previously described [61]. Centromere and BAC signals of 20 metaphases were analyzed per probe combination per cell line.

\section{Microsatellite analysis}

Genomic DNA was isolated from flow-sorted tumour cell subpopulations derived from formalin-fixed, paraffinembedded cervical carcinomas as previously described [62]. Eight fluorescein-labelled primer pairs of microsatellite markers comprising MOGC, D6S265, C125, TY2A, TNF $\alpha$, D6S273, D6S294 and D6S1666 [63], spanning altogether $26 \mathrm{MB}$ from 6p22.1 to 6p12.1, were used. PCR, electrophoresis and analysis was performed as described previously [64]. Comparing normal and tumour DNA, a reduction of more than $50 \%$ of one allele was assigned as complete LOH.

\section{Quantitative real-time PCR (qRT-PCR)}

qRT-PCR was performed as described previously [65]. Expression of the genes of interest was normalized by geometric averaging of multiple internal control genes (CPSF6, HNRPM, EEF1A1, RPL11 and RPL13) using the Genorm program [66]. Out of 5 normalization genes the best 3 were selected using this program; EEF1A1, RPL13 and RPL11. Primer sequences for RPL11 are 5'-ACTTCGCATCCGCAAACTCT (FWD) and 5'-AAGGTGTTGGAGCAGXTCACA (REV). Primer sequences for EEF1A1, RPL13 were reported previously [65]. Commercially available primers were used for TUSC3, ANKH and TRIO (Superarray, Frederick, USA). Primer sequences for SKP2 are: 5'-CCTATCACTCAGTCGGTGCTATGA (FWD) and 5'AATCGTGCCAGATGGTACCCT (REV). To determine differential gene expression between normal cervical epithelial cell cultures (NPE), cell lines with and without 
deletion, gain or amplification, one-way ANOVA was performed.

\section{Authors' contributions}

JK performed RNA isolation, preparation of RNA for microarray hybridization of gene expression arrays, qRTPCR experiments, analysis of array data and preparation of the manuscript. JO performed (integrative) statistical analysis of arrays, interpretation of data and contributed to the preparation of figures. TW supervised hybridization of SNP arrays, contributed to the design of the study and critically reviewed the manuscript. KS supervised technical aspects of array CGH hybridization and critically reviewed the manuscript. JK performed array CGH hybridization. AG contributed to the design of the study and critically reviewed the manuscript. GK contributed to the design of the study and critically reviewed the manuscript. GF contributed to the design of the study and critically reviewed the manuscript. EJ performed DNA isolation, preparation of DNA and microarray hybridization of Affymetrix 10K SNP arrays, FISH experiments, analysis of array data and contributed to the preparation of the manuscript. All authors read and approved the manuscript.

\section{Acknowledgements}

The study was supported by the Dutch Cancer Society, grant no. RUL200 I2465.

\section{References}

I. Narayan G, Pulido HA, Koul S, Lu XY, Harris CP, Yeh YA, Vargas H, Posso H, Terry MB, Gissmann L, Schneider A, Mansukhani M, Rao PH, Murty VV: Genetic analysis identifies putative tumor suppressor sites at $2 \mathrm{q} 35-\mathrm{q} 36.1$ and $2 \mathrm{q} 36.3-\mathrm{q} 37.1$ involved in cervical cancer progression. Oncogene 2003, 22:3489-3499.

2. Melsheimer P, Klaes R, Doeberitz MV, Bastert G: Prospective clinical study comparing DNA flow cytometry and HPV typing as predictive tests for persistence and progression of CIN I/ II. Cytometry 200I, 46:166-17I.

3. Kersemaekers AM, van de Vijver MJ, Kenter GG, Fleuren GJ: Genetic alterations during the progression of squamous cell carcinomas of the uterine cervix. Genes Chromosomes Cancer 1999, 26:346-354.

4. Fan X, Chen JJ: Regulation of cell cycle progression and apoptosis by the papillomavirus E6 oncogene. Crit Rev Eukaryot Gene Expr 2004, 14:183-202.

5. Nishimura M, Furumoto H, Kato T, Kamada M, Aono T: Microsatellite instability is a late event in the carcinogenesis of uterine cervical cancer. Gynecol Oncol 2000, 79:201-206.

6. Rao PH, Arias-Pulido H, Lu XY, Harris CP, Vargas H, Zhang FF, Narayan G, Schneider A, Terry MB, Murty VV: Chromosomal amplifications, $3 q$ gain and deletions of 2q33-q37 are the frequent genetic changes in cervical carcinoma. BMC Cancer 2004, 4:5.

7. Huang FY, Kwok YK, Lau ET, Tang MH, Ng TY, Ngan HY: Genetic abnormalities and HPV status in cervical and vulvar squamous cell carcinomas. Cancer Genet Cytogenet 2005, I 57:42-48.

8. Kersemaekers AM, Hermans J, Fleuren GJ, van de Vijver MJ: Loss of heterozygosity for defined regions on chromosomes 3, I I and 17 in carcinomas of the uterine cervix. Br J Cancer 1998, 77:192-200.

9. Kersemaekers AM, Kenter GG, Hermans J, Fleuren GJ, van de Vijver $\mathrm{MJ}$ : Allelic loss and prognosis in carcinoma of the uterine cervix. Int J Cancer 1998, 79:4 II-4I7.
10. Heselmeyer K, Macville M, Schrock E, Blegen H, Hellstrom AC, Shah $\mathrm{K}$, Auer G, Ried T: Advanced-stage cervical carcinomas are defined by a recurrent pattern of chromosomal aberrations revealing high genetic instability and a consistent gain of chromosome arm 3q. Genes Chromosomes Cancer 1997, 1 9:233-240.

II. Lichter P, Joos S, Bentz M, Lampel S: Comparative genomic hybridization: uses and limitations. Semin Hematol 2000, 37:348-357.

12. Oostlander AE, Meijer GA, Ylstra B: Microarray-based comparative genomic hybridization and its applications in human genetics. Clin Genet 2004, 66:488-495.

13. Ylstra B, van I, Carvalho B, Brakenhoff RH, Meijer GA: BAC to the future! or oligonucleotides: a perspective for micro array comparative genomic hybridization (array CGH). Nucleic Acids Res 2006, 34:445-450.

14. Calhoun ES, Gallmeier E, Cunningham SC, Eshleman JR, Hruban RH, Kern SE: Copy-number methods dramatically underestimate loss of heterozygosity in cancer. Genes Chromosomes Cancer 2006, 45:1070-107I.

15. Zhao X, Li C, Paez JG, Chin K, Janne PA, Chen TH, Girard L, Minna J, Christiani D, Leo C, Gray JW, Sellers WR, Meyerson M: An integrated view of copy number and allelic alterations in the cancer genome using single nucleotide polymorphism arrays. Cancer Res 2004, 64:3060-307I.

16. Huang J, Wei W, Zhang J, Liu G, Bignell GR, Stratton MR, Futreal PA, Wooster R, Jones KW, Shapero MH: Whole genome DNA copy number changes identified by high density oligonucleotide arrays. Hum Genomics 2004, I:287-299.

17. Tsafrir D, Bacolod M, Selvanayagam Z, Tsafrir I, Shia J, Zeng Z, Liu H, Krier C, Stengel RF, Barany F, Gerald WL, Paty PB, Domany E, Notterman DA: Relationship of gene expression and chromosomal abnormalities in colorectal cancer. Cancer Res 2006, 66:2129-2137.

18. Carter SL, Eklund AC, Kohane IS, Harris LN, Szallasi Z: A signature of chromosomal instability inferred from gene expression profiles predicts clinical outcome in multiple human cancers. Nat Genet 2006, 38: 1043-1048.

19. Brewer CA, Setterdahl JJ, Li MJ, Johnston JM, Mann JL, McAsey ME: Endoglin expression as a measure of microvessel density in cervical cancer. Obstet Gynecol 2000, 96:224-228.

20. Harris LN, Yang L, Liotcheva V, Pauli S, Iglehart JD, Colvin OM, Hsieh TS: Induction of topoisomerase II activity after ErbB2 activation is associated with a differential response to breast cancer chemotherapy. Clin Cancer Res 200I, 7:|497-I 504.

21. Hidalgo A, Monroy A, Arana RM, Taja L, Vazquez G, Salcedo M: Chromosomal imbalances in four new uterine cervix carcinoma derived cell lines. BMC Cancer 2003, 3:8.

22. Harris CP, Lu XY, Narayan G, Singh B, Murty VV, Rao PH: Comprehensive molecular cytogenetic characterization of cervical cancer cell lines. Genes Chromosomes Cancer 2003, 36:233-24I.

23. Thein A, Trkova M, Fox M, Parrington J: The application of comparative genomic hybridization to previously karyotyped cervical cancer cell lines. Cancer Genet Cytogenet 2000, I l 6:59-65.

24. Matthews CP, Shera KA, McDougall JK: Genomic changes and HPV type in cervical carcinoma. Proc Soc Exp Biol Med 2000, 223:316-32I.

25. Kirchhoff M, Rose H, Petersen BL, Maahr J, Gerdes T, Lundsteen C, Bryndorf T, Kryger-Baggesen N, Christensen L, Engelholm SA, Philip $\mathrm{J}$ : Comparative genomic hybridization reveals a recurrent pattern of chromosomal aberrations in severe dysplasia/carcinoma in situ of the cervix and in advanced-stage cervical carcinoma. Genes Chromosomes Cancer 1999, 24: I44-I50.

26. Umayahara K, Numa F, Suehiro Y, Sakata A, Nawata S, Ogata H, Suminami Y, Sakamoto M, Sasaki K, Kato H: Comparative genomic hybridization detects genetic alterations during early stages of cervical cancer progression. Genes Chromosomes Cancer 2002, 33:98-102.

27. Ocadiz R, Sauceda R, Cruz M, Graef AM, Gariglio P: High correlation between molecular alterations of the c-myc oncogene and carcinoma of the uterine cervix. Cancer Res 1987, 47:4 |73-4I77.

28. Munzel P, Marx D, Kochel H, Schauer A, Bock KW: Genomic alterations of the c-myc protooncogene in relation to the overexpression of c-erbB2 and $\mathrm{Ki}-67$ in human breast and cervix carcinomas. J Cancer Res Clin Oncol 199I, I I 7:603-607. 
29. Aubele M, Zitzelsberger H, Schenck U, Walch A, Hofler H, Werner $M$ : Distinct cytogenetic alterations in squamous intraepithelial lesions of the cervix revealed by laser-assisted microdissection and comparative genomic hybridization. Cancer 1998, 84:375-379.

30. Sellar GC, Watt KP, Rabiasz G], Stronach EA, Li L, Miller EP, Massie CE, Miller J, Contreras-Moreira B, Scott D, Brown I, Williams AR, Bates PA, Smyth JF, Gabra H: OPCML at I I q25 is epigenetically inactivated and has tumor-suppressor function in epithelial ovarian cancer. Nat Genet 2003, 34:337-343.

31. Mullokandov MR, Kholodilov NG, Atkin NB, Burk RD, Johnson AB, Klinger HP: Genomic alterations in cervical carcinoma: losses of chromosome heterozygosity and human papilloma virus tumor status. Cancer Res 1996, 56:197-205.

32. Mitra AB, Murty VV, Li RG, Pratap M, Luthra UK, Chaganti RS: Allelotype analysis of cervical carcinoma. Cancer Res 1994, 54:448I-4487.

33. Tchurikov NA: Molecular mechanisms of epigenetics. Biochemistry (Mosc) 2005, 70:406-423.

34. Yokoi S, Yasui K, Mori M, lizasa T, Fujisawa T, Inazawa J: Amplification and overexpression of SKP2 are associated with metastasis of non-small-cell lung cancers to lymph nodes. Am J Pathol 2004, 165:175-180.

35. Zheng M, Simon R, Mirlacher M, Maurer R, Gasser T, Forster T, Diener PA, Mihatsch MJ, Sauter G, Schraml P: TRIO amplification and abundant mRNA expression is associated with invasive tumor growth and rapid tumor cell proliferation in urinary bladder cancer. Am J Pathol 2004, 165:63-69.

36. Boing I, Stross C, Radtke S, Lippok BE, Heinrich PC, Hermanns HM Oncostatin $M$-induced activation of stress-activated MAP kinases depends on tyrosine $86 \mathrm{I}$ in the OSM receptor and requires Jak I but not Src kinases. Cell Signal 2006, I 8:50-6I.

37. Loging WT, Reisman D: Elevated expression of ribosomal protein genes L37, RPP-I, and S2 in the presence of mutant p53. Cancer Epidemiol Biomarkers Prev 1999, 8: 101 I-1016.

38. la Cour JM, Mollerup J, Winding P, Tarabykina S, Sehested M, Berchtold MW: Up-regulation of ALG-2 in hepatomas and lung cancer tissue. Am J Pathol 2003, 163:8I-89.

39. Jiang F, Caraway NP, Li R, Katz RL: RNA silencing of S-phase kinase-interacting protein 2 inhibits proliferation and centrosome amplification in lung cancer cells. Oncogene 2005, 24:3409-34I8.

40. Dowen SE, Neutze DM, Pett MR, Cottage A, Stern P, Coleman N, Stanley MA: Amplification of chromosome 5p correlates with increased expression of Skp2 in HPV-immortalized keratinocytes. Oncogene 2003, 22:253 I-2540.

4I. Ho AM, Johnson MD, Kingsley DM: Role of the mouse ank gene in control of tissue calcification and arthritis. Science 2000 289:265-270.

42. Coe BP, Henderson LJ, Garnis C, Tsao MS, Gazdar AF, Minna J, Lam S, Macaulay C, Lam WL: High-resolution chromosome arm 5p array CGH analysis of small cell lung carcinoma cell lines. Genes Chromosomes Cancer 2005, 42:308-313.

43. Zhang A, Zheng C, Hou M, Lindvall C, Wallin KL, Angstrom T, Yang $X$, Hellstrom AC, Blennow E, Bjorkholm M, Zetterberg A, Gruber A, $\mathrm{Xu}$ D: Amplification of the telomerase reverse transcriptase (hTERT) gene in cervical carcinomas. Genes Chromosomes Cancer 2002, 34:269-275.

44. Huang FY, Chiu PM, Tam KF, Kwok YK, Lau ET, Tang MH, Ng TY, Liu VW, Cheung AN, Ngan HY: Semi-quantitative fluorescent PCR analysis identifies PRKAAI on chromosome 5 as a potential candidate cancer gene of cervical cancer. Gynecol Oncol 2006, 103:219-225.

45. Levy A, Dang UC, Bookstein R: High-density screen of human tumor cell lines for homozygous deletions of loci on chromosome arm 8p. Genes Chromosomes Cancer 1999, 24:42-47.

46. Lerebours F, Olschwang S, Thuille B, Schmitz A, Fouchet P, Buecher B, Martinet N, Galateau F, Thomas G: Fine deletion mapping of chromosome 8p in non-small-cell lung carcinoma. Int J Cancer |999, 8 |:854-858.

47. Wilting SM, Snijders PJ, Meijer GA, Ylstra B, van den ljssel PR, Snijders AM, Albertson DG, Coffa J, Schouten JP, van de Wiel MA, Meijer C], Steenbergen RD: Increased gene copy numbers at chromosome $20 \mathrm{q}$ are frequent in both squamous cell carcinomas and adenocarcinomas of the cervix. J Pathol 2006, 209:220-230.
48. Tanner MM, Grenman S, Koul A, Johannsson O, Meltzer P, Pejovic T, Borg A, Isola J: Frequent amplification of chromosomal region 20q I 2-q I 3 in ovarian cancer. Clin Cancer Res 2000, 6: I 833- I839.

49. Yang SH, Seo MY, Jeong HJ, Jeung HC, Shin J, Kim SC, Noh SH, Chung $\mathrm{HC}$, Rha SY: Gene copy number change events at chromosome 20 and their association with recurrence in gastric cancer patients. Clin Cancer Res 2005, I I :6 I 2-620.

50. Wong LJ, Dai P, Lu JF, Lou MA, Clarke R, Nazarov V: AIB I gene amplification and the instability of poly $Q$ encoding sequence in breast cancer cell lines. BMC Cancer 2006, 6: III.

5I. van Dekken H, Vissers K, Tilanus HW, Kuo WL, Tanke HJ, Rosenberg C, ljszenga M, Szuhai K: Genomic array and expression analysis of frequent high-level amplifications in adenocarcinomas of the gastro-esophageal junction. Cancer Genet Cytogenet 2006, 166:157-162.

52. Koopman LA, Szuhai K, van Eendenburg JD, Bezrookove V, Kenter GG, Schuuring E, Tanke H, Fleuren G): Recurrent integration of human papillomaviruses 16, 45, and 67 near translocation breakpoints in new cervical cancer cell lines. Cancer Res 1999 , 59:5615-5624.

53. Hazelbag S, Fleuren GJ, Baelde JJ, Schuuring E, Kenter GG, Gorter A: Cytokine profile of cervical cancer cells. Gynecol Oncol 200I, 83:235-243.

54. Miller SA, Dykes DD, Polesky HF: A simple salting out procedure for extracting DNA from human nucleated cells. Nucleic Acids Res 1988, 16:1215.

55. Knijnenburg J, Szuhai K, Giltay J, Molenaar L, Sloos W, Poot M, Tanke $\mathrm{HJ}$, Rosenberg C: Insights from genomic microarrays into structural chromosome rearrangements. Am J Med Genet A 2005, I32:36-40.

56. Ensembl 2007 [http://www.ensembl.org]

57. Irizarry RA, Hobbs B, Collin F, Beazer-Barclay YD, Antonellis KJ, Scherf U, Speed TP: Exploration, normalization, and summaries of high density oligonucleotide array probe level data. Biostatistics 2003, 4:249-264.

58. Gautier L, Cope L, Bolstad BM, Irizarry RA: affy--analysis of Affymetrix GeneChip data at the probe level. Bioinformatics 2004, 20:307-3I5.

59. Eilers $\mathrm{PH}$, de Menezes RX: Quantile smoothing of array CGH data. Bioinformatics 2005, 2 I: I | 46- I I53.

60. Kleinfeld RG, Sisken JE: Morphological and kinetic aspects of mitotic arrest by and recovery from colcemid. J Cell Biol 1966, 31:369-379.

61. Wiegant J, Ried T, Nederlof PM, van der PM, Tanke HJ, Raap AK: In situ hybridization with fluoresceinated DNA. Nucleic Acids Res I991, 19:3237-324I.

62. Corver WE, Ter Haar NT, Dreef EJ, Miranda NF, Prins FA, Jordanova ES, Cornelisse CJ, Fleuren G]: High-resolution multi-parameter DNA flow cytometry enables detection of tumour and stromal cell subpopulations in paraffin-embedded tissues. J Pathol 2005, 206:233-24l.

63. The GDB Human Genome Database 2007 [http:// www.GDB.org/].

64. Haven CJ, van Puijenbroek M, Karperien M, Fleuren GJ, Morreau H: Differential expression of the calcium sensing receptor and combined loss of chromosomes Iq and I Iq in parathyroid carcinoma. J Pathol 2004, 202:86-94.

65. Kloth JN, Fleuren GJ, Oosting J, de Menezes RX, Eilers PH, Kenter GG, Gorter A: Substantial changes in gene expression of Wnt, MAPK and TNFalpha pathways induced by TGF-betal in cervical cancer cell lines. Carcinogenesis 2005, 26: | 493-| 502.

66. Vandesompele J, De Preter K, Pattyn F, Poppe B, Van Roy N, De Paepe A, Speleman F: Accurate normalization of real-time quantitative RT-PCR data by geometric averaging of multiple internal control genes. Genome Biol 2002, 3:RESEARCH0034. 